\title{
MATHEMATICAL THEORY AND EXPERIMENT
}

\section{OF FLOOD WAVES}

\author{
(Trans. of JSCE Sept. 1953) \\ By Dr. Eng., Taizu HAYASHI, C. E. Member*
}

\begin{abstract}
Synopsis This paper describes mathematical theory and laboratory experiment of the flood wave in uniform open channel. The theory is developed by the method of successive approximations with respect to a small parameter $\sigma$ which is defined by $\sigma=\sqrt{-\ddot{F}(\mathrm{O}) / g} / S_{0}$, whree $\ddot{\vec{F}}$ (O) denotes the vertical accelerative rate of rising of the stage of the flood wave at the moment of passage of its crest at a cross section of the channel, $g$ the intensity of gravity and $S_{0}$ slope of the channel. The laboratory experiment was conducted primarily for the verification of the theory. Flood wave with any desired value of $\sigma$ was generated in flowing water with any desired. value of Froude number and specifically the rate of attenuation and the speed of propagation, both of which were related to the crest of the wave, were measured and are compared with: those given by the theory.
\end{abstract}

\section{INTRODUCTION}

Since the pioneering work by Kleitz $[1]]^{* *}$ appeared in 1877 many mathematical treatments of the flood wave have been presented. It having been impossible to. solve rigorously the basic equations of the flood wave, different assumptions were based on for developing the solution of the problem and, thus, different aspects of the problem were dealt with under different assumptions. The theoretical treatments. of the flood wave, however, would roughly be classified as follows: (i) Analytical treatment under the neglection of the equation of motion [1-3], (ii) analytical treatment under the assumption of sufficiently small amplitude of the wave [4-15], (iii) analytical treatment under the main assumption that the total or at least local acceleration term in the equation of motion of the wave is negligible [16-22 and 23], (iv) analytical treatment of the flood wave in totally horizontal channel [24], (v) analytical treatment under the main assumption that the speed of propagation of the wave differs little from the theoretical velocity of waves without friction [25-26], (vi) treatment by method of graphical integration of the basic equation [27], (vii) partly graphical treatment by means of Massau's equations of characteristics. [28-33], and (viii) others [34].

The graphical treatments will be more useful than the analytical ones for practical purposes such as flood routing. Instead, in order to derive laws for the flood wave characteristics the analytical methods will be more effective than the graphical treatments. In fact, two important characteristics, i. e. the subsidence, and the speed of propagation, of the wave crest, have been studied by the analytical treat-

* Assistant Professor, Dept. of Civil Eng., Faculty of Eng., Chūō University

Research Scholar, Institute of Science and Technology, University of Tōkyō

** Figures in square brackets indicate the literature references at the end of this paper. 
ments. However, any of the analytical treatments is not systematic enough to permit to estimate the error in the formulas whereby derived, so the accuracy of the approximation of the treatments is quite questionable. Abandoning any of the above cited assumptions for this reason, the author systematically develops the solution of the problem based upon a more appropriate assumption than any other. Furthermore, there having been few reliable results of experiments on both the subsidence and the speed of propagation, of the flood wave, the experiment conducted by the author primarily for the verification of his theory is presented.

\section{MATHEMATICAL THEORY}

\section{THE BASIC EQUATIONS}

Consider a uniform open channel of a rectangular cross section with a constant width $B$ and take the $x$-axis along the bottom of the channel and the $H$-axis vertically upwards. $H$ represents the water depth in the channel and $S_{0}$ the channel slope. Let $U$ and $Q$ denote the average velocity of the particles in, and the discharge per unit width through, a cross section at $x$, respectively. Then the equation of continuity is

$$
\frac{\partial H}{\partial t}=-\frac{\partial Q}{\partial x}
$$

where $t$ is time. As the resistance law it is desired to adopt the Manning's law

$$
U=(1 / \gamma) R^{2 / 3} S_{f}^{1 / 2}
$$

where $R$ is hydraulic mean depth, $S_{f}$ frictional slope, and $r$ equal to Kutter's roughness $n$ in metric system and to $n / 1.49$ in foot system. Using the law, the equation of motion is written

$$
\frac{\partial U}{\partial t}+U_{\frac{\partial U}{\partial x}}=-g \frac{\partial H}{\partial x}+g S_{0}-g \frac{\gamma^{2} U^{2}}{R^{4 / 3}}
$$

where $g$ is the intensity of gravity. Substitution of the relation $U=Q / H$ in the above equation yields

$$
\left(1-\frac{Q^{2}}{g H^{3}}\right) \frac{\partial H}{\partial x}+2 \frac{Q}{g H^{2}} \frac{\partial Q}{\partial x}+\frac{1}{g H} \frac{\partial Q}{\partial t}=S_{0}-\frac{\gamma^{2} Q^{2}}{H^{2} R^{4 / 3}}
$$

Both the equations ( 1 ) and ( 3 ) constitute the basic equations.

\section{NON-DIMENTIONALIZATION}

Let us assume that the hydrograph and hence the time-water depth diagram of a flood wave at a cross section, say at the origin of a channel, is given. Let us take the origin of time at the time of occurence of the peak of the flood wave and let the diagram be expressed by the formula $H=F(t)$ (cf. Fig. 1). The main purpose of the present theory is to furnish formulas relating how fast the wave propagates downstream and how much the wave
Fig. 1. Time-water depth diagram of the flood wave at the origin of channel.

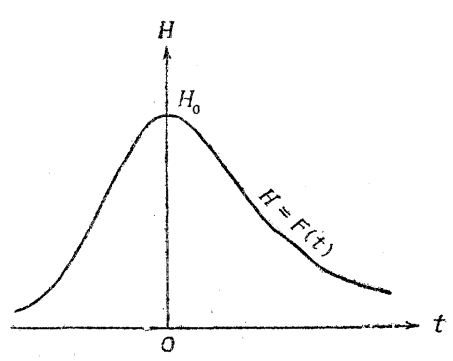


gets deformed as it propagates downstream.

In order to non-dimensionalize the basic equations let us make the following linear transformations:

$$
\left\{\begin{array}{l}
h=H / H_{0} \\
q=Q / \sqrt{g H_{0}{ }^{3}} \\
b=B / H_{0} \\
\tau=t / \sqrt{H_{0} /-\ddot{F}(0)} \\
\xi=x / \sqrt{g H_{0}{ }^{2} /-\ddot{F}(0)}
\end{array}\right.
$$

Wherein $H_{0}$ is the depth at $t=0$ at the origin of the channel (cf. Fig. 1), $\ddot{\boldsymbol{F}}(0)$ the value of $\partial^{2} \boldsymbol{F} / \partial t^{2}$ at $t=0$, and $h, q, b, \tau$, and $\xi$ are the non-dimensionalized forms of water depth, discharge per unit width, the width of the channel, time, and the distance from the origin of the channel, respectively. Substitution of (4) in the basic equations (1) and (3) gives

$$
\frac{\partial h}{\partial \tau}+\frac{\partial q}{\partial \xi}=0
$$

and

$$
\sigma\left(1-\frac{q^{2}}{h^{3}}\right) \frac{\partial h}{\partial \xi}+2 \sigma \frac{q}{h^{2}} \frac{\partial q}{\partial \xi}+\sigma \frac{1}{h} \frac{\partial q}{\partial \tau}=1-\frac{r^{2} g}{H_{0}^{1 / 3} S_{0}} \frac{q^{2}}{h^{10 / 3}}\left(1+\frac{2 h}{b}\right)^{\frac{4}{3}}
$$

where

$$
\sigma=\sqrt{-\ddot{F}(0) / g} / S_{0}
$$

Let $Q_{0}, R_{0}$ and $\mathbf{F}$ denote the discharge per unit width, the hydraulic mean depth and the Froude number, respectively, for uniform flow at the depth $\boldsymbol{H}_{0}$. Then

$$
\mathbf{F}=Q_{0}{ }^{2} /\left(g H_{0}{ }^{3}\right)
$$

and by Manning's law

$$
Q_{0}=H_{0}\left(R_{0}^{2 / 3} S_{0}^{1 / 2} / \gamma\right)
$$

where

$$
R_{0}=H_{0} B /\left(B+2 H_{0}\right)
$$

Combination of the last three equations gives

$$
\mathbf{F}^{2}=H_{0}{ }^{1 / 3}\{1+(2 / b)\}^{-4 / 3} S_{0} /\left(r^{2} g\right)
$$

Substitution of ( 8 ) in the second term of the right member of (6) yields

$$
\sigma\left(1-\frac{q^{2}}{h^{3}}\right) \frac{\partial h}{\partial \xi}+2 \sigma \frac{q}{h^{2}} \frac{\partial q}{\partial \xi}+\sigma \frac{1}{h} \frac{\partial q}{\partial \tau}=1-\frac{1}{\mathbf{F}^{2}}\left(1+\frac{2}{b}\right)^{-4 / 3} \cdot \frac{q^{2}}{h^{10 / 3}}\left(1+\frac{2 h}{b}\right)^{4 / 3}
$$

which, together with (5), constitutes the desired forms of the basic equations.

Next, let us consider about the boundary condition. The time-water depth relation at the origin of the channel is to be used as a boundary condition, which is

$$
H=F(t)
$$

(see Fig. 1). Substitution of the first and the fourth formulas of (4) into the above relation gives

$$
h=\left(1 / H_{0}\right) F\left(\sqrt{H_{0} /-\ddot{F}(0)} \cdot \tau\right)
$$


Putting

$$
\left(1 / H_{0}\right) F\left(\sqrt{H_{0} /-\ddot{F}(0)} \cdot \tau\right)=f(\tau)
$$

the last equation is written

$$
h=f(\tau)
$$

which becomes the desired non-dimensionalized form of the boundary condition. In view of Fig. 1 it is easily seen that

$$
f(0)=1 \quad \text { and } \quad f^{\prime}(0)=0
$$

It is also seen from (11) that

$$
f^{\prime \prime}(0)=-1
$$

\section{THE FIRST APPROXIMATION}

Since the vertical accelerative rate of rising of the stage at the crest of the flood wave is very small compared with the acceleration of gravity, $\sigma$, in view of (7), is easily understood to be a small quantity compared with unity in most channels with slope. Hence neglection of all the terms having the multiplier $\sigma$ in (9) will give the first approximation. Thus, from (9) there is obtained

$$
q_{1}=\mathbf{F}\left(1+\frac{2}{b}\right)^{2 / 3} h_{1}^{5 / 3}\left(1+\frac{2 h_{1}}{b}\right)^{-2 / 3}
$$

where $h_{1}$ and $q_{1}$ are the values of the first approximation of water depth and discharge per unit width, respectively. Then substitution of (15) in (5) yields

$$
\frac{\partial h_{1}}{\partial \tau}+\mathbf{F}\left(1+\frac{2}{b}\right)^{2 / 3} h_{1}^{2 / 3}\left(1+\frac{2 h_{1}}{b}\right)^{-5 / 3}\left(\frac{5}{3}+\frac{2 h_{1}}{b}\right) \frac{\partial h_{1}}{\partial \xi}=0
$$

which is the equation for $h_{1}$. By a theory of partial differential equations [35] the solution of the above partial differential equation is given by the solution of the following ordinary simultaneous equations:

$$
\frac{\mathrm{d} \tau}{1}=\frac{\mathrm{d} \xi}{\mathbf{F}\left(1+\frac{2}{b}\right)^{2 / 3} h_{1}^{2 / 3}\left(1+\frac{2 h_{1}}{b}\right)^{-5 / 3}\left(\frac{5}{3}+\frac{2 h_{1}}{b}\right)}=\frac{\mathrm{d} h_{1}}{0}
$$

The last member of (17) is integrated to

$$
h_{1}=C
$$

where $C$ is an integration constant. Integration of the equation of the first and the second member of (17), after the substitution of (18) in the second member, yields.

$$
\tau=\frac{\mathrm{d} \xi}{\mathbf{F}\left(1+\frac{2}{b}\right)^{2 / 3} C^{2 / 3}\left(1+\frac{2 C}{b}\right)^{-5 / 3}\left(\frac{5}{3}+\frac{2 C}{b}\right)}+C \text { for } h_{1}=C
$$

where $C_{1}$ is another integration constant. By the theory of partial differential equations the general solution, therefore, is given by

$$
h_{1}=G\left[\tau-\frac{\xi}{\mathbf{F}\left(1+\frac{2}{b}\right)^{2 / 3} h_{1}{ }^{2 / 3}\left(1+\frac{2 h_{1}}{b}\right)^{-5 / 3}\left(\frac{5}{3}+\frac{2 h_{1}}{b}\right)}\right]
$$

where $G$ is an arbitrary function. While the boundary condition, as described in the: previous section, is given by 


$$
h_{1}=f(\tau) \quad \text { at } \quad \xi=0
$$

Hence, the function $G$ being determined,

$$
h_{1}=f\left[\tau-\frac{\xi}{\mathbf{F}\left(1+\frac{2}{b}\right)^{2 / 3} h_{1}^{2 / 3}\left(1+\frac{2 h_{1}}{b}\right)^{-5 / 3}\left(\frac{5}{3}+\frac{2 h_{1}}{b}\right)}\right]
$$

which is the desired first approximate solution in non-dimensionalized form for water depth of the flood wave. From (21) it is understood that the value of the first approximation for the speed of propagation of particles on the flood wave is given by

$$
\omega=\mathbf{F}\left(1+\frac{2}{b}\right)^{2 / 3} h_{1}^{2 / 3}\left(1+\frac{2 h_{1}}{b}\right)^{-5 / 3}\left(\frac{5}{3}+\frac{2 h_{1}}{b}\right)
$$

and the value of the first approximation for the propagation speed of the crest of the wave by

$$
\omega_{0}=\mathbf{F}\left(1+\frac{2}{b}\right)^{-1}\left(\frac{5}{3}+\frac{2}{b}\right)
$$

since $h_{1}=1$ at the crest of the wave at the channel. It is also seen from (18) and (19) that each value of water depth propagates with a constant speed of propagation and the value of water depth remains constant as it propagates downstream. Thus, by the first approximation, the crest of the flood wave propagates downstream with the speed given by (23) and without any change of its height. The change of

Fig. 2. Change of the shape of the flood wave by the first approximation.

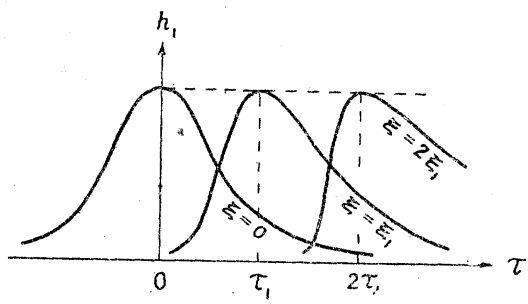
the shape of the wave by the first approximation would somewhat be like shown in Fig. 2.

\section{THE SECOND APPROXIMATION}

The accuracy of the first approximation having been insufficient for obtaining the law of attenuation of the flood wave, the second approximation is needed. In order to analyse the motion of the crest of the flood wave let us now restrict our attention only near the crest and follow the movement of it. From (21) and (23) it is understood that the path of the movement of the crest of the wave by the first approximation is given by $\xi=\omega_{0} \tau$ on the $\tau-\xi$ plane. Let $\Delta \xi$ and $\Delta \tau$ denote the deviations from the path towards the direction of $\xi$ and $\tau$, respectively. Then, on the path line $h_{1}$ is expanded as

$$
h_{1}=1+\frac{1}{2 !}\left(\Delta \tau \frac{\partial}{\partial \tau}+\Delta \xi \frac{\partial}{\partial \xi}\right)^{2} h_{1}+
$$

where the first derivatives vanish due to (13). Substituting (24) and (23) in the right member of (21) and considering that both $\Delta \xi$ and $\Delta \tau$ are small quantities compared with' unity near the path line,

$$
\begin{aligned}
h_{1} & =f\left[\tau-\left(\xi / \omega_{0}\right)\left\{1+O\left(\overline{\Delta \tau^{2}}, \Delta \tau \Delta \xi, \overline{\Delta \xi^{2}}\right)\right\}\right] \\
& =f\left[\tau-\left(\xi / \omega_{0}\right)\left\{1+O\left(\overline{\Delta \tau^{2}}\right)\right\}\right]
\end{aligned}
$$

where $O$ denotes the order of the magnitude of its arguments. Near the path line 
the above expression is further expanded as

$$
\begin{aligned}
h_{1} & =f(0)+(1 / 2 !) f^{\prime \prime}(0)\left[\theta-\left(\xi / \omega_{0}\right) O\left(\bar{\Delta} \tau^{2}\right)\right]^{2} \\
& =f(0)+(1 / 2 !) f^{\prime \prime}(0) \theta^{2}+O\left(\theta \cdot \overline{\Delta \tau^{2}}\right) \ldots \ldots \ldots
\end{aligned}
$$

where

$$
\theta=\tau-\left(\xi / \omega_{0}\right)
$$

Substituting (13), (14) and (27) in (26),

$$
h_{1}=1-\frac{1}{2 !}\left(\tau-\frac{\xi}{\omega_{0}}\right)^{2}+O\left[\left(\tau-\frac{\xi}{\omega_{0}}\right)^{5}\right]
$$

For obtaining the second approximation near the crest of the flood wave let us now substitute the values of the first approximation in the left member of (9) whose terms all are of the magnitude of the order of $\sigma$. Thus (9) becomes

$$
\sigma K \cdot\left(\tau-\frac{\xi}{\omega_{0}}\right)+O\left[\sigma\left(\tau-\frac{\xi}{\omega_{0}}\right)^{2}\right]=1-\frac{1}{\mathbb{F}^{2}}\left(1+\frac{2}{b}\right)^{-4 / 3} \frac{q^{2}}{h^{10 / 3}}\left(1+\frac{2 h}{b}\right)^{4 / 3}
$$

where

$$
K=\frac{1}{\mathbf{F}} \frac{3(b+2)}{5 b+6}\left\{1-\left(\frac{2}{3} \mathbf{F} \frac{b}{b+2}\right)^{2}\right\}
$$

From (29)

$$
q=\mathbf{F}[1+(2 / b)]^{2 / 3} h^{5 / 3}[1+(2 h / b)]^{-2 / 3}\left[1-(\sigma / 2) K \cdot\left\{\tau-\left(\xi / \omega_{0}\right)\right\}+O\left\{\sigma \cdot\left(\tau-\xi / \omega_{0}\right)^{2}\right\}\right]
$$

Neglection of $O\left[\sigma \cdot\left\{\tau-\left(\xi / \omega_{0}\right)\right\}^{2}\right]$ in the above equation compared with unity yields

$$
q_{2}=\mathbf{F}[1+(2 / b)]^{2 / 3} h_{2}{ }^{5 / 3}\left[1+\left(2 h_{2} / b\right)\right]^{-2 / 3}\left[1-(\sigma / 2) K \cdot\left\{z-\left(\xi / \omega_{0}\right)\right\}\right]
$$

where $h_{2}$ and $q_{2}$ represent the values of the second approximation for water depth and discharge per unit width, respectively.

Meanwhile, the equation of continuity, which the variables of the second approximation must satisfy, is

$$
\frac{\partial h_{2}}{\partial r}+\frac{\partial q_{2}}{\partial \xi}=0
$$

Substitution of (31) in (32) and neglection of $O\left[\sigma \cdot\left(\tau-\xi / \omega_{0}\right)\right]$ compared with unity yield

$$
\begin{aligned}
& \frac{\partial h_{2}}{\partial \tau}+\mathbf{F}\left(1+\frac{2}{b}\right)^{2 / 3} h_{2}^{2 / 3}\left(1+\frac{2 h_{2}}{b}\right)^{-5 / 3}\left(\frac{5}{3}+\frac{2 h_{2}}{b}\right) \frac{\partial h_{2}}{\partial \xi}=-\frac{\sigma}{2}\left(1+\frac{2}{b}\right)^{5 / 3}\left(\frac{5}{3}+\frac{2}{b}\right)^{-1} \\
& \cdot K h_{2}{ }^{5 / 3}\left(1+\frac{2 h_{2}}{b}\right)^{-2 / 3} \ldots \ldots \ldots \ldots \ldots \ldots \ldots \ldots \ldots \ldots \ldots \ldots \ldots \ldots \ldots \ldots \ldots \ldots \ldots \ldots \ldots \ldots \ldots \ldots \ldots \ldots \ldots \ldots \ldots \ldots \ldots \ldots \ldots \ldots \ldots \ldots \ldots \ldots \ldots \ldots \ldots
\end{aligned}
$$

By the theory of partial differential equations referred to in the previous section. the solution of the above partial differential equation is given by that of the following ordinary simultaneous equations:

$$
\begin{aligned}
\frac{\mathrm{d}:}{1} & =\frac{\mathrm{d} \xi}{\mathbf{F}\left(1+\frac{2}{b}\right)^{2 / 3} h_{2}^{2 / 3}\left(1+\frac{2 h_{2}}{b}\right)^{-5 / 3}\left(\frac{5}{3}+\frac{2 h_{2}}{b}\right)} \\
& =\frac{\mathrm{d} h_{2}}{-\frac{\sigma}{2}\left(1+\frac{2}{b}\right)^{5 / 3}\left(\frac{5}{3}+\frac{2}{b}\right)^{-1} K h_{2}^{5 / 3}\left(1+\frac{2 h_{2}}{b}\right)^{-2 / 3}} .
\end{aligned}
$$

The equation of the second and the third members is reduced after cancellation to

$$
-\frac{\sigma}{2 \mathbf{F}}\left(1+\frac{2}{b}\right)\left(\frac{5}{3}+\frac{2}{b}\right)^{-1} K \mathrm{~d} \xi=\frac{(5 / 3)+\left(2 h_{2} / b\right)}{\left\{1+\left(2 h_{2} / b\right)\right\} h_{2}} \mathrm{~d} h_{2}
$$

The above equation is easily integrated to 


$$
\exp \left[-\frac{3 \sigma}{10 \mathbf{F}}\left(1+\frac{2}{b}\right)\left(\frac{5}{3}+\frac{2}{b}\right)^{-1} K \xi\right]=C_{2} \frac{h_{2}}{\left\{1+\left(2 h_{2} / b\right)\right\}^{2 / 5}}
$$

where $C_{2}$ is an integration constant. The water depth of the crest of the flood wave at the origin of the channel $(\xi=0)$ being 1 , the value of the integration constant is determined by the condition

$$
h_{2}=1 \quad \text { at } \quad \xi=0
$$

Thus $C_{2}$ is ${ }^{\text {iddetermined as }}$

$$
C_{2}=\{1+(2 / b)\}^{2 / 5}
$$

Substituting (37) in (35),

$$
\exp \left[-\frac{3 \sigma}{10 \mathbf{F}}\left(1+\frac{2}{b}\right)\left(\frac{5}{3}+\frac{2}{b}\right)^{-1} K \xi\right]=\left\{\frac{1+(2 / b)}{\left(1+\left(2 h_{2} / b\right)\right.}\right\}^{2 / 5} h_{2}
$$

which is the desired formula for the attenuation of the crest of the flood wave with respect to the distance.

Next, from the equation of the first and the second members of (34) it is obviously given that

$$
\omega_{2}=\mathbf{F}\left(1+\frac{2}{b}\right)^{2 / 3} h_{2}^{2 / 3}\left(1+\frac{2 h_{2}}{b}\right)^{-5 / 3}\left(\frac{5}{3}+\frac{2 h_{2}}{b}\right)
$$

where $\omega_{2}$ is the value of the second approximation. Meanwhile, denoting $U_{u}, Q_{u}$ and $R_{u}$ the velocitiy, the discharge per unit width and the hydraulic mean depth, respectively, all for the uniform flow at the depth $H$,

$$
Q_{u}=U_{u} H=\left(\frac{1}{n} R_{u}{ }^{2 / 3} S_{0}{ }^{1 / 2}\right) \cdot H=\frac{1}{n} H^{5 / 3}\left(1+\frac{2 H}{B}\right)^{-2 / 3} S_{0}^{1 / 2}
$$

Therefore

$$
\frac{\mathrm{d} Q_{u}}{\mathrm{~d} H}=\frac{1}{n} H_{0}^{2 / 3} h^{2 / 3}\left(1+\frac{2 h}{b}\right)^{-5 / 3}\left(\frac{5}{3}+\frac{2 h}{b}\right) S_{0}^{1 / 2} \cdots
$$

The combination of (39), (40) and (8) yields

$$
\omega_{2}=\left(1 / \sqrt{g H_{0}}\right)\left(\mathrm{d} Q_{\mathrm{u}} / \mathrm{d} H\right)
$$

Denoting the non-dimensionalized form of $Q_{\mathrm{u}}$ by $q_{\mathrm{u}}$, the above formula is reduced to

$$
\omega_{2}=\frac{\mathrm{d} q_{\mathrm{u}}}{\mathrm{d} h}
$$

which coincides with the well-known Kleitz-Seddon law.

\section{FORMULAS OF THE SECOND APPROXIMATION FOR WIDE RECT - ANGULAR CHANNELS}

In channels of wide rectangular cross section where $O\left(h_{2} / b\right)$ is negligible compared with unity (38) is reduced to

$$
h_{2}=\exp \left[-\sigma \frac{27}{250}\left(\frac{1}{\mathbf{F}^{2}}-\frac{4}{9}\right) \xi\right]
$$

Let $\lambda$ denote the factor of the rate of attenuation of the water depth of the crest of the flood wave, then from (43)

$$
\lambda=\sigma \frac{27}{250}\left(\frac{1}{\mathbf{F}^{2}}-\frac{4}{9}\right)
$$


whose magnitude is plotted in Fig. 3.

By being reverted to original dimensions (43) and (42) become

$H=H_{0} \exp \left[\frac{27}{250}\left(\frac{1}{\mathbf{F}^{2}}-\frac{4}{9}\right) \frac{\ddot{F}(0)}{g H_{0} S_{0}} x\right]$

and

$$
W=\frac{\mathrm{d} Q_{\mathrm{u}}}{\mathrm{d} H}=\frac{5}{3} U_{\mathrm{u}}
$$

respectively, where $W$ is the speed of propagation of the crest of the wave in its original dimension.

\section{FORMULAS OF THE SECOND APPROXIMATION FOR SHORT REACHES}

For comparatively short reaches it may be reasonable to put

$$
[2+(2 / b)] /[1+(2 h / b)] \div 1
$$

Then (38) is reduced to

$$
h_{2}=\exp \left[-\frac{27}{10} \sigma\left(\frac{b+2}{5 b+6}\right)^{2}\left\{\frac{1}{\mathbf{F}^{2}}-\frac{4}{9}\left(\frac{b}{b+2}\right)^{2} \xi\right\}\right]
$$

Whence the factor of the rate of attenuation of the water depth of the crest of the flood wave is given as

$$
\alpha=\frac{27}{10} \sigma\left(\frac{b+2}{5 b+6}\right)^{2}\left\{\frac{1}{1 \mathbf{F}^{2}}-\frac{4}{9}\left(\frac{b}{b+2}\right)^{2}\right\}
$$

By being reverted to original dimensions, (47) becomes

$$
H=H_{0} \exp \left[\frac{27}{10}\left(\frac{B+2 H_{0}}{5 B+6 H_{0}}\right)^{2}\left\{\frac{1}{\mathbf{F}^{2}}-\frac{4}{9}\left(\frac{B}{B+2 H_{0}}\right)^{2}\right\} \frac{\ddot{F}(0)}{g H_{0} S_{0}} x\right]
$$

(48) is further expanded as

$$
\Delta H=\frac{27}{10}\left(\frac{B+2 H_{0}}{5 B+6 H_{0}}\right)^{2}\left\{\frac{1}{\mathbf{F}^{2}}-\frac{4}{9}\left(\frac{B}{B+2 H_{0}}\right)^{2}\right\} \frac{\ddot{F}(0)}{g H_{0} S_{0}} \Delta x
$$

where $\Delta H$ represents the subsidence of the wave crest in the distance $\Delta x$.

The speed of propagation given by (39) becomes in the original dimensions

$$
W=\frac{\mathrm{d} Q_{\mathrm{u}}}{\mathrm{d} H}=\frac{5 B+6 H}{3(B+2 H)} U_{\mathrm{u}}
$$

while introduction of the relation

$$
\ddot{F}(0) \mathrm{t} \doteqdot \dot{F}=\partial \boldsymbol{H} / \partial t
$$

into (29) gives for flood discharge per unit width

$$
Q=Q_{u}\left[1-\frac{1}{S_{0} W} \frac{\partial H}{\partial t}\left\{1-\left(\frac{2}{3} \mathbf{F} \frac{B}{B+2 H_{0}}\right)^{2}\right\}\right]^{1 / 2}
$$

which corresponds to the Jones formula (e. g. [36]).

If the hydrograph in the vicinity of its maximum stage is considered to be the segment of a parabola subtended by a chord joining two equal values of stages less than the maximum stage, it is possible to evaluate $\dddot{F}(0)$ in terms of the length of 
the chord $M_{t}$ and the rise $M_{H}$ measured from the midpoint of the chord to the crest stage as

$$
\ddot{F}(0)=-8 M_{H} / M_{t}^{2}
$$

Substitution of (52) in (49) gives

$$
\Delta H=-\frac{216}{10}\left(\frac{B+2 H_{0}}{5 B+6 H_{0}}\right)^{2}\left\{\frac{1}{\mathrm{~F}^{2}}-\frac{4}{9}\left(\frac{B}{B+2 H_{0}}\right)^{2}\right\} \frac{M_{H}}{g H_{0} S_{0} M_{l}{ }^{2}} \Delta x
$$

The subsidence of the flood wave in the natural river with complex natural flowing conditions will be determined by dividing the river into successive short reaches and then applying the above formula to each reach.

\section{COMPARISON BETWEEN THE THEORY AND DATA OF FIELD EXPERIMENT}

Fig.4 shows data of field experiment of a small flood in the River Edo, Japan in December 1943 conducted by the Kantō Regional Bureau of the Ministry of Construction of Japan [37]. The river practically has uniform width of about $80 \mathrm{~m}$ in average. The necessary data for
Fig. 4. Field experiment of a flood wave in the River Edo (Kantō Regional Bureau, Ministry of Construction Japan).

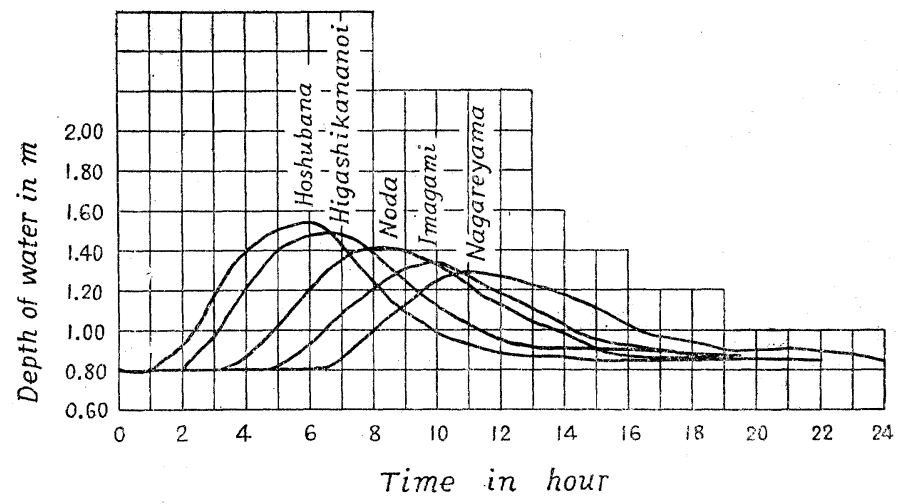

the calculation of the subsidence of the flood wave are:

$$
H_{0}=1.54 \mathrm{~m}, \quad n=0.026, \quad S_{0}=1 / 3,600
$$

and $\quad \ddot{F}(0)=-0.05 \mathrm{~m} /(30 \mathrm{~min})^{2}=-1.542 \times 10^{-8} \mathrm{~m} / \mathrm{sec}^{2}$.

Plotting the distance and the maximum depth of water during the flood on semi-logarithm scale gives Fig. 5, which illustrates the theory presented by (45) is in a very good agreement with the experiment.

Letting $L$ and $T_{\exp }$
Fig. 5. Maximum water depth-distance diagram for the flood of the previous figure.

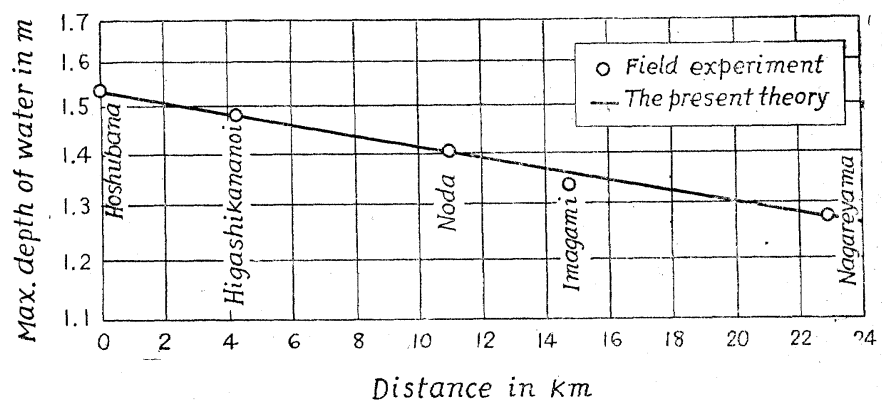

represent the distance between Hōshubana and Nagareyama and the time required for the wave to pass through the reach between the two stations, respectively, the experimental value of the speed of propagation of the wave is given as

$$
W_{\text {exp }}=L / T_{\text {exp }}=22,943 \mathrm{~m} / 5.06 \mathrm{hr}=1.26 \mathrm{~m} / \mathrm{sec}
$$

While, the theoretical value of the speed of propagation by (50) is

$$
W=1.29 \mathrm{~m} / \mathrm{sec}
$$


which is also in good agreement with the experimental value.

\section{LABORATORY EXPERIMENT}

\section{STUDY OF BASIC REQUIREMENTS}

In view of the process of the derivation of the theory, it is easily seen that the value of $\sigma$ of the flood wave is less than unity, so that the terms on the left member of (9) may be regarded as trivial terms. On the contrary the value of $\sigma$ of the long wave would be infinitely large, so conversely the right member of (9) may be negligible compared with the other member. Strictly, a wave in an open channel is considered to have both long wave characteristics and flood wave characteristics. But if $\sigma>1$, the wave should rather be regarded as a long wave than a flood wave and if $\sigma<1$, it should rather be considered as a flood wave than a long wave. Thus the value of $\sigma$ of a wave may be a measure to discriminate the type of the wave. In the experiment of the flood wave, therefore, the wave of value of $\sigma$ less than unity should be generated. In view of that, previous experiment of the wave conducted at laboratory [38] is considered partly unsatisfactory. The present exeriment being to be concerned with the verification of the theory developed in the previous part through the confirmation of eqs (47. a) and (50), any desired value of Froude number and $\sigma$ should readily be realized. In addition, $\sigma$ being primarily related to the value of the accelerative rate of the stage of the crest of the flood wave, the wave at the origin of channel is desired to be approximately of sinusoidal shape with regard to time so that determination of the accelerative rate of the stage may most precisely be done.

\section{DESCRIPTION OF APPARATUS AND ARRANGEMENTS}

The essentials of apparatus and arrangements of the experiment are shown in Fig. 6 and Fig. 7. Essentially the apparatus consists of the following components:

Fig. 6. General view of flood wave channel looking downstream and water suppiy system.

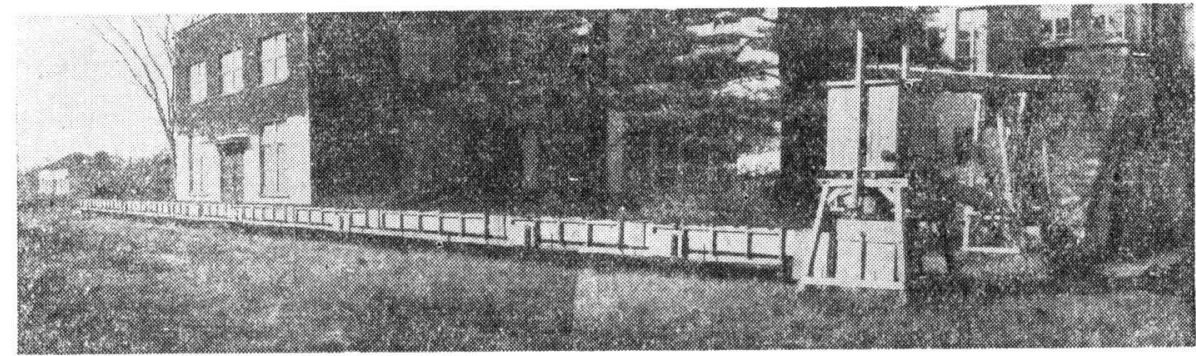

(i) Flood Wave Channel of Non-return Type A wooden flume at Kawada Laboratory of the Institute of Science and Technology of University of Tōkyō was used for the experiment. It has rectangular cross section, with the smaller dimension 
Fig. 7. Flood wave generating system.
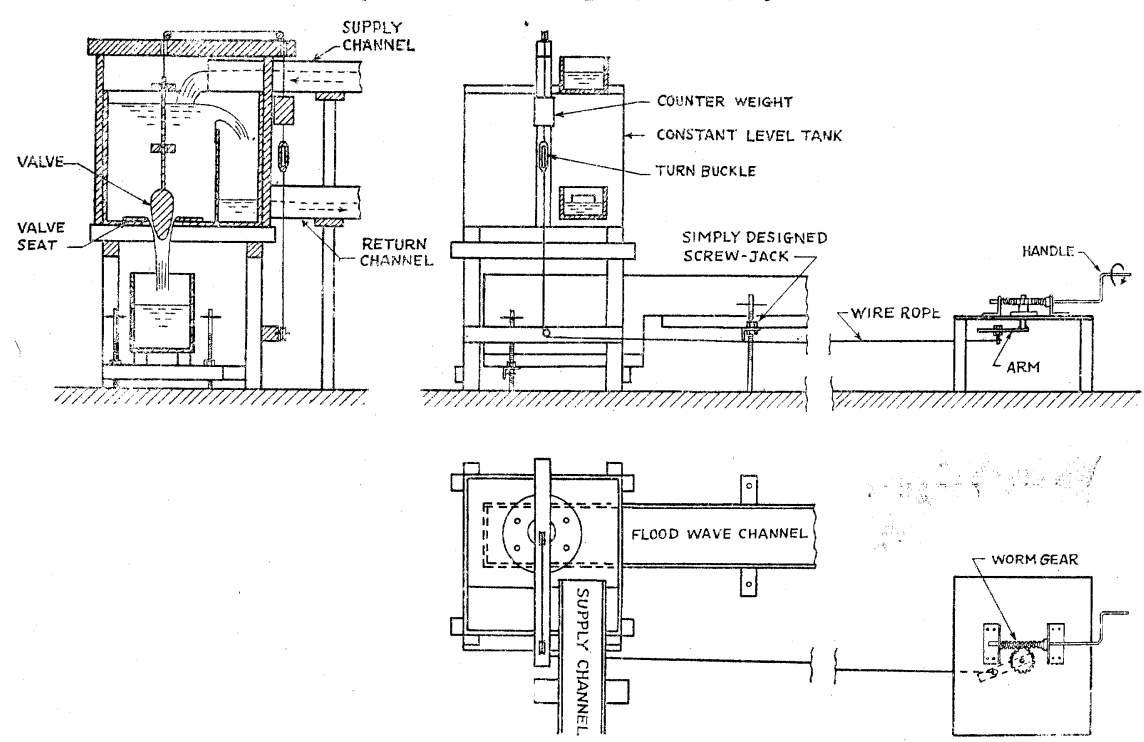

vertical, with cross sectional dimensions of $30 \mathrm{~cm} \times 40 \mathrm{~cm}$. Total length of the channel is approximately $33 \mathrm{~m}$ and, due to its large dimension, it was constructed outdoors behind the laboratory. Variation of the longitudinal slope of it is provided for by means of simply designed screw-jack supports. Any desired value of Froude number is obtained by adjusting the slope to satisfy the formula

$$
\mathbf{F}=(1 / n) R^{2 / 3} S_{0}^{1 / 2} / \sqrt{g H_{0}}
$$

(ii) Water Supply System Directly above the upstream end of the flood wave channel a constant level tank is constructed (seen nearly at the center of Fig. 6), to which sufficient amount of water is constantly supplied by a supply flume from a larger concrete-lined head tank. Excess water of the former tank is returned by a return flume to a large concrete-lined reservoir from which water is constantly pumped up to the larger head tank.

(iii) Flood Wave Generating System At the bottom of the constant level tank a valve is inserted, which is operated as a kind of a specially designed needle valve. It is displaced sinusoidally with respect to time by means of a revolution of an arm fixed to the axis of an worm gear (see Fig. 7). The shape of the valve has been designed so as to provide the rate of discharge proportional to its displacement. Hence, the rate of discharge for the flood wave of sinusoidal form may be provided at the origin of the flood wave channel by a revolution of the arm of the worm gear. Both the speed of revolution, and the length, of the arm, are arbitrarily adjustable. Therefore a flood wave of any desired value of $\sigma$ and wave height is readily generated.

\section{EXPERIMENTAL PROCEDURE}

Along the flood wave channel at six stations of $5.50 \mathrm{~m}$ in each distance water depths in the channel are led to each buoy chamber (Fig. 8). By means of a buoy, a pair of frictionless pulleys and a string the amount of water depth at each sta- 
tion is directly transmitted to a recording place (Fig. 9), where the amounts of the water depths at the six stations are simultaneously recorded by photographical means.

\section{EXPERIMENTAL RESULTS}

The experimental results of the rate of attenuation of the crest of the flood wave are plotted in Fig. 10 covering the entire range of experiments. Theoretical curves expressed by (47.a) for $b=4.5 \mathrm{~cm} / 40 \mathrm{~cm}=0.1125$ are also
Fig. 8. Buoy and buoy chamber.

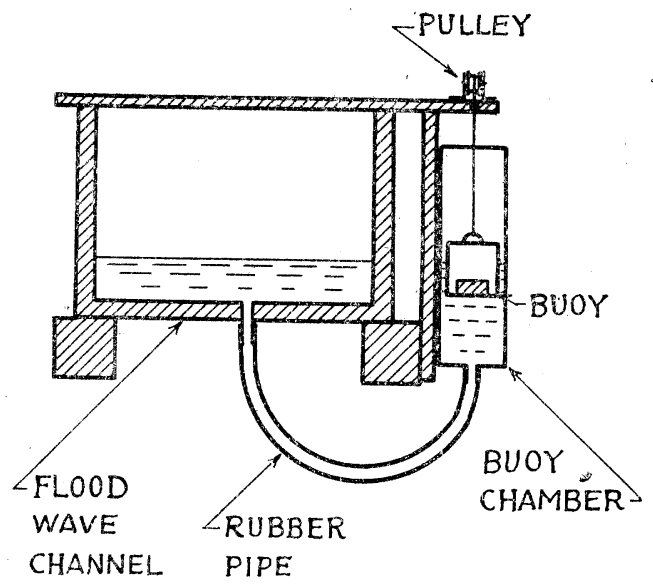
shown in the figure.

In Table 1 the experimental results of the speed of propagation of the flood wave are tabulated.
Fig. 9. Diagram of the arrangement to transmitt the amount of water depths at six stations to a common reading place.

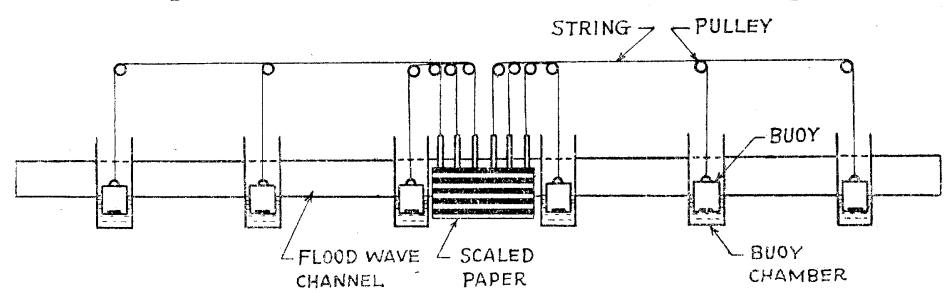

Fig. 10. The factor of attenuation of the flood wave.

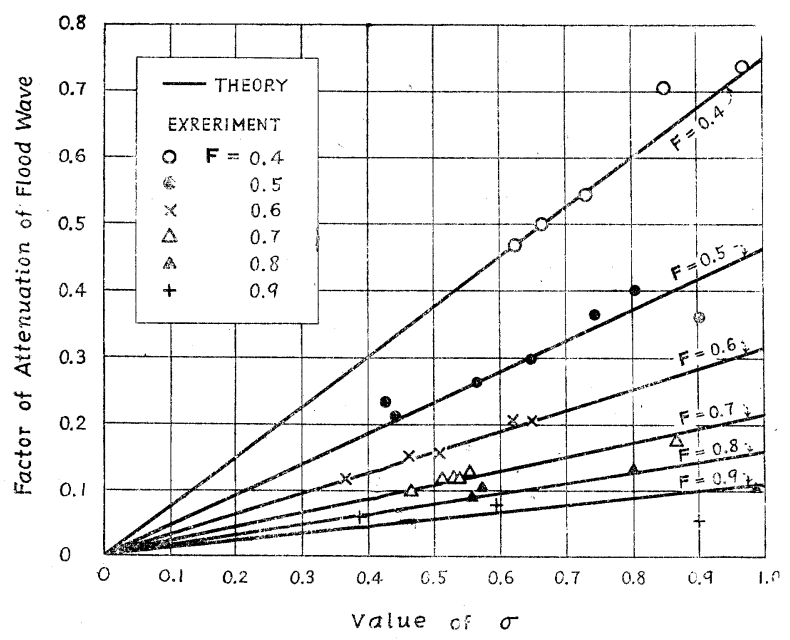

\section{CONCLUSIONS}

By the method of successive approximation with respect to the small parameter $\sigma$, the solution of the second approximation was obtained. The error of the solution in percentage is considered to be the order of the magnitude of $100 \sigma^{2}$. $\sigma$ defined by (7) is found to be a measure to discriminate the type of a water wave in open channels, i. e., if $\sigma>1$, the

water wave rather be regared as a long wave than a flood wave and if $\sigma<1$, conversely. Main laws derived by the solution are as follows: (i) The subsidence of the flood wave is most generally given by (38), for the wide rectangular channel by (45), and for the short reach by either (49) or (53), all of which are essentially the improved formulas for the formula by Forchheimer or Bachet-Callet. (ii) The speed of propagation of the wave is most generally given by (50), which is the same as Kleitz-Seddon law. (iii) The flood discharge at the vicinity of the crest of the wave is given by (51), which is the improved formula for the Jones formula. 
Table 1. Experimental and theoretical results of the speed of propagation of the flood wave.

\begin{tabular}{|c|c|c|c|c|c|}
\hline \multirow{2}{*}{$\begin{array}{l}\text { Run } \\
\text { No. }\end{array}$} & \multirow{2}{*}{$\mathbf{F}$} & \multirow{2}{*}{$\sigma$} & \multicolumn{3}{|c|}{ Speed of Propagation } \\
\hline & & & $\begin{array}{l}\text { Exp. } \\
(\mathrm{cm} / \mathrm{s})\end{array}$ & $\begin{array}{l}\text { Theory } \\
(\mathrm{cm} / \mathrm{s})\end{array}$ & $\underset{(\%)}{\text { Diff. }}$ \\
\hline 7 & 0.6 & 0.510 & 67.8 & 63.1 & 7.5 \\
\hline 8 & 0.6 & 0.367 & 61.1 & 64.2 & -4.8 \\
\hline 9 & 0.7 & 0.470 & 76.3 & 76.9 & -0.8 \\
\hline 10 & 0.7 & 0.547 & 79.7 & 79.5 & 0.3 \\
\hline 12 & 0.7 & 0.562 & 70.5 & 68.8 & 2,5 \\
\hline 13 & 0.7 & 0.525 & 70.5 & 70.3 & 0.3 \\
\hline 15 & 0.7 & 0.863 & 73.8 & 74.7 & -1.2 \\
\hline 16 & 0.8 & 0.976 & 83.3 & 84.3 & -1.2 \\
\hline 17 & 0.8 & 0.571 & 84.6 & 86.7 & -2.4 \\
\hline 19 & 0.8 & 0.557 & 87.3 & 86.7 & 0.7 \\
\hline 20 & 0.8 & 0.801 & 100.0 & 88.7 & 11.3 \\
\hline 21 & 0.9 & 0.900 & 115.9 & 91.8 & 26.3 \\
\hline 23 & 0.9 & 0.290 & 87.3 & 96.9 & -9.9 \\
\hline 24 & 0.9 & 0.591 & 100.0 & 99.6 & 0.4 \\
\hline
\end{tabular}

By the experiment both the rate of attenuation and the speed of propagation, of the crest of the flood wave, were measured and compard with the theory. The results are summarized in Fig. 10 and in Table 1. Although the accuracy of the experiment is not all that might be desired, the experimental results are considered to be enough to verify the theory.

\section{ACKNOWLEDGEMENT}

The author acknowledges gratefully Prof. Dr. Sanji KAWADA for his supervision and kind guidance. Grateful acknowledgements are also made

to Professors Dr. Masashi HOMMA, Dr. Takeo MOGAMI and Dr. Ryūma KAWAMURA for their guidance and encouragement; to Mr. Hideo KIKKAWA, Mr. Kan-ichi HIROOKA and Dr. Shigeo UCHIDA for their very valuable suggestions given to him; to Mr. Kiyoshi UDAGAWA, Mr. Kazuyuki ISHIKAWA and Mr. Mitsuyoshi NAKANISHI for their assistance and cooperation at the experiment.

A part of the expenses of the experiment was indebted to the scientific research fund grant from the Ministry of Education of Japan.

\section{LITERATURE REFERENCES}

1) Keitz: Théorie du mouvement non permanent des liquides et sur son application à la propagation des crues des rivières, Annales des Ponts et Chaussées, 1877, pp. 133-196.

2) Ph. Forchheimer: Hydraulik, Teubner,Leipzig u. Berlin, 1930, p. 292.

3) E. E. Moots: A study in the theory of flood-waves, Trans. American Geophysical Union, 1938, Part I, pp. 383-386.

4) P. Alibrandi: Sur la théorie des ondes de crues, Annali d'Ingeniera e d'Architettura, mai-juin, 1917.

5) Edmond Maillet: Étude sur le mouvement graduellement varié non permanent et la propagation des crues, Ann. Ponts et Ch., 1919-III, pp. 289-330.

6) Bonneau: Étude sur la propagation des crues, Ann. Ponts et Ch.,1924-III, pp. $282-325$.

7) Pierre Massé: L'amortissement des intumescences, Revue Générale de l'Hydraulique, 1935, pp. $300-308$.

8) Ph. Deymie: Propagation d'une intumescence allongée, Revue Gén. de l'Hyd., 1935, pp. 138-142.

9) Pierre Massé : Hydrodynamique fluviale-Regimes variables, Hermann Paris, 1935.

10) A. M. Angelini : 1'Elettrotecnica, 1936, p. 486.

11) Carlo Drioli : Esperienze sul moto perturbato nei canali industriali (Onde di translazione), 1'Energia Elettrica, Aprile, 1937, pp. 285-311.

12) L. Cagniard: Hydrodynamique fluviale_-Regimes variables, Revue Gén. de l'Hyd., MaiJuin, 1937, pp. 128-136.

13) Ph. Deymie: Propagation d'une intumescence allongée (probleme aval), Proc. Fifth Inter- 
national Congress of Applied Mechanics, John Wiley, New York, 1939, pp. 537-544.

14) G. D. Ransford: Remarque sur la théorie du premier ordre des ondes de translation, La Houille Blanche, Sept.-Oct., 1951, pp. 758-760.

15) Taizo Hayashi : Mathematical study of the motion of intumescences in open channels of uniform slope, Trans. Japan Soc. Civ. Eng., No. 11, Dec., 1951, pp. 1-11.

16) B. E. Jones: A method of correcting river discharge for a changing stage, U. S. Geological Survey Water Supply Paper 375-E, 1915, p. 117:

17) Ph. Forchheimer: 1. c. ante pp. 299-302.

18) J. A. Koženy: Die Wasserführung der Flüsse, Franz Deuticke, Leipzig u. Wien, 1920, pp. 60-61.

19) Bonneau: 1. c. ante.

20) Bachet: Note sur la propagation et l'annonce des crues, Ann. Ponts et Ch., 1934-III, pp. 409-463.

21) Callet: Note sur la prevision des crues, Ann. Ponts et Ch., 1937-I, pp. 37-46.

22) C. J. Posey: Flood wave characteristics as related to flood routing, Proc. Second Hydraulics Conference, Univ. of Iowa Studies in Eng., Bulletin 27, 1943.

23) Edomond Maillet: 1. c. ante.

24) M. A. Biot: Quadratic wave equation-Flood wave in a channel with quadratic friction, Proc. of the National Academy of Sciences, Vol. 21, July, 1935, pp.436-443.

25) J. Boussinesq: Essai sur la théorie des eaux courantes, Mémoires divers Savants a l'Academie des Sciences, Vol.23, 1877.

26) G. H. Keulegan \& G. W. Patterson: Effect of turbulence and channel slope on translation waves, Journal of Research of the National Bureau of Standards, Vol. 30, June, 1943, pp. 461-512.

27) H. A. Thomas: Graphical integration of the flood-wave equations, Trans. Amer. Geophy. Un., Apr., 1940, pp. 596-602.

28) J. Massau: L'intégration graphique, Ann. de l'association des ingénieurs sortis des Écoles Spéciales de Gand, Vol. 12, 1889, p. 435.

29) J. Massau: Mémoire sur l'intégration graphique des équations aux dérivées partielles, Ann. del' association des ingénieurs sortis des Écoles Spéciales de Gand, Vol. 23, 1900, p. 95.

30) A. Craya: Calcul des régimes variables dans les canaux, La Houille Blanche, Vol. 1, 1945-46, p. 19.

31) R. Ré: Étude du lâcher instantane d'une retenue d'eau dans un canal par la méthode graphique, La Houille Blanche, Vol. 1, Nov. 3, 1946.

32) H. J. Putman: Unsteady flow in open channels, Trans. Amer. Geophy. Un., Apr., 1948, pp. 227-232.

33) P. N. Lin: Numerical Analysis of continuous unsteady flow in open channels, Trans. Amer. Geophy. Un., Apr. 1952, pp. 226-234.

34) Shōitirō Hayami: On the propagation of flood waves, Disaster Prevention Research Institute; Kyōto Univ., Bulletin No. 1, Dec., 1951, pp. 1-16.

35) A. R. Forsyth: A treatise on Differential Equations, Cambridge Univ. Press, Ed. 6, 1928 , p. 401.

36) Hunter Rouse: Engineering Hydraulics, John Wiley, 1949, p. 654.

37) Hideo Kikkawa: On the flood wave (in Japanese), Doboku-kenky $\bar{u}$, Vol. 1, Rokumei Publishing House, Tokyo, Nov., 1948, pp. 61-78.

38) R. E. Horton: Seddon's and Forchheimer's formula for crest-velocity of flood-waves subject to channel-friction control, Trans. Amer. Geophy. Un., 1938, Part I, pp. 374-382. 